\title{
Two roads diverged in the right ventricular outflow tract
}

\author{
Leora B. Balsam, MD, ${ }^{\mathrm{a}}$ and Abe DeAnda, $\mathrm{Jr}, \mathrm{MD}^{\mathrm{b}}$
}

\author{
From the ${ }^{\mathrm{a} D i v i s i o n}$ of Cardiac Surgery, UMass Memorial Medical Center, Worcester, Mass; and ${ }^{\mathrm{b}}$ Division of Car- \\ diovascular and Thoracic Surgery, University of Texas Medical Branch-Galveston, Galveston, Tex. \\ Disclosures: Authors have nothing to disclose with regard to commercial support. \\ Received for publication Nov 18, 2017; accepted for publication Dec 2, 2017; available ahead of print Jan 23, \\ 2018. \\ Address for reprints: Leora B. Balsam, MD, Division of Cardiac Surgery, UMass Memorial Medical Center, 55 \\ Lake Ave North, Worcester, MA 01655 (E-mail: leora.balsam@umassmemorial.org). \\ J Thorac Cardiovasc Surg 2018;155:1445-6 \\ $0022-5223 / \$ 36.00$ \\ Copyright (c) 2017 by The American Association for Thoracic Surgery \\ https://doi.org/10.1016/j.jtcvs.2017.12.029
}

The Ross procedure is a palliative strategy that finds its place in the management of aortic valve disease in children and young adults. Its advantages include potential for autograft growth, restoration of normal hemodynamics, and avoidance of anticoagulation. The durability of the Ross procedure is limited by failures on the autograft side as well as the reconstructed right ventricular outflow tract (RVOT). Reintervention on the autograft is more frequent in the adult population, whereas reintervention on the RVOT is more common in the pediatric population. The German Dutch Ross Registry of more than 2000 patients who underwent the Ross procedure reported that in adults, autograft reintervention occurred at a rate of $1.03 \%$ per patient-year and homograft reintervention at a rate of $0.65 \%$ per patient-year; this was in contrast to the pediatric population in whom autograft reintervention occurred at a rate of $0.91 \%$ per patient-year and homograft reintervention at a rate of $2.72 \%$ per patient-year. ${ }^{1}$

A frequent criticism of the Ross procedure is that it converts single-valve disease into double-valve disease. The potential benefits of an autograft must be weighed against risks related to future reintervention. The Mayo group reported a spectrum of reoperations in 56 patients who underwent the Ross procedure, which included autograft valve replacement, aortic root replacement, pulmonic valve replacement, ascending and arch reconstruction, and tricuspid valve surgery. ${ }^{2}$ In their series, early mortality was $1.8 \%$; however, significant morbidity occurred in $16 \%$ of patients. In recent years, options for reintervention on the RVOT side have broadened to include transcatheter pulmonary valve replacement (TPVR), which offers the potential for less-invasive management of conduit valve degeneration. Current TPVR platforms include the Melody valve (Medtronic, Minneapolis, Minn) and the SAPIEN valve (Edwards Lifesciences, Irvine, Calif). ${ }^{3-5}$ In most reports, procedural success is nearly $100 \%$ for TPVR in pulmonary homografts and heterografts, with restitution of a competent valve and improvement in gradients. In the early experience with the Melody valve, stent fracture

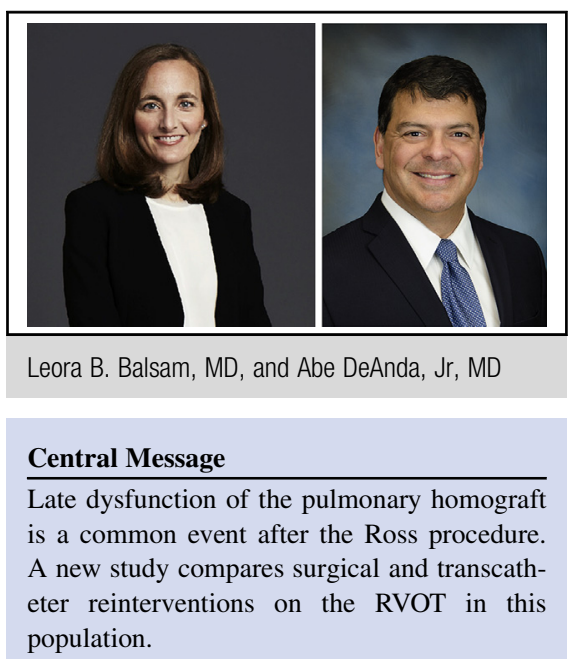

See Article page 1434.

was a frequent failure mechanism leading to recurrent RVOT obstruction and/or valve incompetence, occurring in $20 \%$ to $30 \%$ of cases. As the technical experience has grown, the practice of prestenting has reduced the incidence of stent fracture to less than $5 \% .{ }^{6}$ Investigators in the US Melody Investigational Device Exemption (IDE) trial reported 5-year freedom from reintervention and explantation of $76 \pm 4 \%$ and $92 \pm 3 \%$, respectively. Lessons learned from the Melody valve have been carried over to the SAPIEN platform, which also appears to have good short-term results.

In this issue of the Journal, Alassas and colleagues ${ }^{7}$ evaluate their experience with pulmonary homograft reinterventions (TPVR and surgical) in the adult (age $\geq 14$ years) Ross population. Their experience spans 25 years, during which time 88 of 548 patients $(16 \%)$ underwent reintervention for pulmonary homograft dysfunction. Approximately one half of these patients had TPVR and one half had surgical PVR. The authors grapple with the question of whether one therapy is better than the other and quickly find out that they are comparing apples to oranges. Fifty-nine percent of the patients in the surgical PVR group had concomitant valvular disease and/or coronary artery disease requiring correction, suggesting that the decision to refer for TPVR versus surgical PVR was strongly influenced by the need for additional surgical procedures. Although there were no procedural deaths, one third of the patients had a suboptimal hemodynamic result. For the TPVR group, the majority of suboptimal results were high residual pulmonic valve gradients. 
For the surgical PVR group, suboptimal results included moderate or greater isolated pulmonic regurgitation, high residual gradients, or both. This finding begs the obvious question of what can be done to achieve a better early hemodynamic result. Interestingly, the authors find that, over time, there was greater progression of pulmonic valve dysfunction in the surgical PVR group than in the TPVR group. This did not translate into differences in reintervention, highlighting the fact that freedom from reintervention is not a reliable surrogate for valvular dysfunction.

Another interesting finding was a greater rate of infective endocarditis (IE) in the TPVR group compared with the surgical group ( $13 \%$ vs $0 \%)$. The median time to presentation was 68 months after valve replacement, with an annualized rate of IE in the TPVR group of $2.98 \%$ per patient-year. As has been reported elsewhere, ${ }^{8,9}$ when IE occurred, it was often life-threatening. IE after TPVR has been a hot topic, and in the balance of the existing literature, it has not been clear whether the risk is greater than after surgical PVR, or any other type of valve replacement for that matter. Some of the problems with the literature in this area include lack of uniformity in reporting practices and outcome definitions, heterogeneity in the patient population undergoing TPVR, and an overall small number of cases. The findings of Alassas and colleagues ${ }^{7}$ are an important contribution in this area.

The future is technology-driven, and it is likely that TPVR will continue to take a larger foothold in the lifetime management of patients after the Ross procedure. Although the technology and technique are not perfect, one can expect modifications and improvements in the years to come. Ideally, these changes will broaden the pool of patients to whom it can be offered without increasing procedural risk and cost. Currently, a major risk with TPVR is coronary compression, and the standard is to perform dynamic testing before TPVR with concomitant balloon inflation in the RVOT and coronary angiography to identify this catastrophic problem. Patients who undergo the Ross procedure have 3 times the risk of coronary compression compared with patients who do not undergo the Ross procedure $(9 \%$ vs $3 \%)$, as was demonstrated in a post-hoc analysis of the 3 Melody TPVR trials. ${ }^{10}$ Another future frontier will be timing of the RVOT intervention. As technology improves to provide a reliable early and late outcome, earlier intervention will also become more palatable.

\section{References}

1. Charitos EI, Takkenberg JJM, Hanke T, Gorski A, Botha C, Franke U, et al. Reoperations on the pulmonary autograft and pulmonary homograft after the Ross procedure: an update on the German Dutch Ross Registry. J Thorac Cardiovasc Surg. 2012;144:813-23.

2. Stulak JM, Burkhart HM, Sundt TM, Connolly HM, Suri RM, Schaff HV, et al Spectrum and outcome of reoperations after the Ross procedure. Circulation. 2010;122:1153-8.

3. Armstrong AK, Balzer DT, Cabalka AK, Gray RG, Javois AJ, Moore JW, et al. One-year follow-up of the Melody transcatheter pulmonary valve multicenter post-approval study. JACC Cardiovasc Interv. 2014;7:1254-62.

4. Cheatham JP, Hellenbrand WE, Zahn EM, Jones TK, Berman DP, Vincent JA, et al. Clinical and hemodynamic outcomes up to 7 years after transcatheter pulmonary valve replacement in the US Melody Valve Investigational Device Exemption Trial. Circulation. 2015;131:1960-70.

5. Wilson WM, Benson LN, Osten MD, Shah A, Horlick EM. Transcatheter pulmonary valve replacement with the Edwards Sapien system: the Toronto experience. JACC Cardiovasc Interv. 2015;8:1819-27.

6. Hascoet S, Acar P, Boudjemline Y. Transcatheter pulmonary valvulation: current indications and available devices. Arch Cardiovasc Dis. 2014;107: 625-34.

7. Alassas K, Mohty D, Clavel MA, Husain A, Hijji T, Aljoufan M, et al. Transcatheter versus surgical valve replacement for the failed pulmonary homograft in the Ross population. J Thorac Cardiovasc Surg. 2018;155:1434-44.

8. McElhinney DB, Benson LN, Eiken A, Kreutzer J, Padera RF, Zahn EM. Infective endocarditis after transcatheter pulmonary valve replacement using the Melody valve: combined results of 3 prospective North American and European Studies. Circ Cardiovasc Interv. 2013;6:292-300.

9. McElhinney DB. Making sense of the literature on endocarditis after transcatheter pulmonary valve replacement. Circ Cardiovasc Interv. 2017;10: e004983.

10. Gillespie MJ, McElhinney DB, Kreutzer J, Hellenbrand WE, El-Said H, Ewert P, et al. Transcatheter pulmonary valve replacement for right ventricular outflow tract conduit dysfunction after the Ross procedure. Ann Thorac Surg. 2015; 100:996-1003. 